\title{
New money for mental health: will it make things better for rural and remote Australia?
}

\author{
James A Dunbar, lan B Hickie, John Wakerman and Prasuna Reddy
}

M ental disorders make up a large and increasing proportion of the burden of disease. ${ }^{l}$ With modern treatments, $40 \%$ of that burden can be averted. ${ }^{2}$ However, because of the inefficiency of the health system, only $13 \%$ is averted. ${ }^{3}$ This is particularly true for rural and remote regions, ${ }^{4}$ with hard mental health indicators, such as suicide rates, demonstrating this service failure - only well-serviced areas have experienced a fall in rates. ${ }^{5}$

In May 2006, the federal Minister for Health announced the allocation of $\$ 1.9$ billion for mental health over the next 5 years, and the Council of Australian Governments has agreed to a National Action Plan on Mental Health involving all governments. In relation to rural and remote areas, the Minister said in the press release:

People living in rural and remote Australia are no exception to the "one in five" rate of mental illness in the population. However, for people in these locations, distance and availability of appropriate services can complicate treatment and management of common mental disorders.

$\$ 51.7$ million over five years will see people living in rural and remote Australia having better access to mental health services. Complementing the new MBS [Medicare Benefits Schedule] mental health items for GPs [general practitioners] and psychiatrists, this measure will allow more people in rural and remote locations to access services from appropriately trained social workers, psychologists, occupational therapists and Aboriginal health workers. ${ }^{6}$

\section{What will the new money be used for?}

When the Better Outcomes in Mental Health Care (BOiMHC) initiative was introduced in 2001, it proved the usefulness to GPs and their patients of increased access to psychological services. ${ }^{4}$ The new funding for mental health from November 2006 means that this initiative has been extended and strengthened, and all GPs, psychiatrists and paediatricians are able to use MBS item numbers 2710,2712 and 2713 to refer their patients to psychologists and other trained therapists, to develop more integrated care plans, to work more closely with other primary and secondary care professionals, and to follow up shared patients. Innovative general practices are forging better mental health systems for their patients, and we expect such systems to now develop rapidly.

From a community perspective, ${ }^{4,7}$ the most significant change in the BOiMHC is the extension of MBS item numbers to registered psychologists, social workers and occupational therapists. For psychologists, there will be two categories - general psychology and specialist clinical psychology. All Medicare services will be limited to a maximum of 12 individual sessions, with a review by the referring doctor after the initial six sessions. In addition, patients will also be eligible for 12 group sessions. All patients who are assessed as having a mental disorder, as defined in the MBS, are eligible for these new services. This includes patients with the high-prevalence disorders seen commonly in general practice, such as depression, anxiety, adjustment disorder, and substance use disorders, as well as people needing bereavement counselling.

\section{ABSTRACT}

- New Australian government funding for the Better Outcomes in Mental Health Care initiative is a significant step forward for mental health, with general practitioners now able to offer direct referrals to psychologists, social workers, occupational therapists and Aboriginal health workers.

- Incentives for better teamwork between GPs and other mental health professionals have been introduced, but may have unintended consequences, including an exacerbation of workforce shortages in rural and remote areas.

- Possible solutions to these shortages include rural scholarships for students in the mental health professions; recruitment and retention of students coordinated by university departments of rural health; better access to continuing professional development; and federally funded rural positions and additional financial incentives for rural mental health practitioners.

MJA 2007; 186: 587-589

\section{Will the changes improve services outside the major urban centres?}

Undoubtedly, this is the best news for mental health services in many years, ${ }^{7}$ but there is concern as to whether it will deliver services outside the major urban centres. Access to mental health services in rural areas is limited by distance, expense, transport, and the difficulty of recruiting health professionals to these areas. ${ }^{4,8}$ Inequity in the provision of mental health services in rural areas is striking. Among the limitations of the previous BOiMHC initiative were the workforce shortages in rural and remote areas. The mental health workforce is very unevenly distributed. MBS claims by psychiatrists have been falling since the mid 1990s, although more providers are making claims. ${ }^{9}$ These claims range from $\$ 73.79$ per capita per annum in inner south-east Melbourne to $\$ 0.31$ in rural Western Australia. ${ }^{3}$ In short, psychiatrists are reducing the number of services they provide, but increasing the cost of each service to the patient, and providing the service privately. $^{9}$

There are also quite disproportionate numbers of psychologists practising in metropolitan centres. For example, while $45 \%$ of Queenslanders live in rural areas, only $13 \%$ of psychologists reside there. For Victoria, the comparative figures are $23 \%$ versus $2.6 \%{ }^{10}$ We can only assume that psychological services, like those of psychiatrists, will now become more available where service providers reside and where the population can make the additional co-payments, leading to further movement away from rural to metropolitan areas and an even greater inequity of provision. We cannot wait until subsequent monitoring demonstrates further losses. Proactive strategies, not only by governments, but also by professional and educational and training bodies, are urgently required. 
Suggested additional responses to lack of access to outpatient mental health services in rural and remote Australia

\section{Current problem Recent government responses}

1. Lack of access to general practitioners for mental health services

- Continuing payments for GPs who provide specific mental health assessments or nonpharmacological interventions

\section{Suggested solutions}

- A national primary care strategy with funding for organisational development

- Organisational and training support for development of multidisciplinary teams based in general practice

- Specific financial incentives for GPs who provide mental health services in rural and remote regions

- Direct employment of trained medical graduates by government or Divisions of General Practice

2. Lack of access to - New Medicare Benefits Schedule (MBS) clinical psychology items for psychologists and other allied and other health professionals

evidence-based - New funding for specific rural and regional services schemes

$\begin{array}{ll}\text { 3. Lack of access } & \text { - Telepsychiatry } \\ \text { to specialised } & \text { - New psychiatry item numbers for } \\ \text { psychiatric } & \text { assessment } \\ \text { assessment } & \text { - Higher payments to psychiatrists for first } \\ & \text { assessments } \\ & \text { - New MBS items for group sessions }\end{array}$

4. Lack of access

to e-health-based

innovations

- Bursaries for nursing and psychology students undertaking placements in rural and remote areas

- Improved access to continuing professional development for mental health professionals in rural and remote areas

- Direct employment of non-medical mental health professionals through Divisions of General Practice and directly through larger general practices

- Access to experts in organisational development

- Support for training and development of nurse practitioner roles

- Obligation on GPs, psychiatrists and psychologists claiming Better Outcomes in Mental Health Care MBS item numbers not to charge a gap fee

- Specific incentives for providing services to those living in rural and remote areas

- Direct employment of specialists by government to provide services

- New models of mixed private- and public-sector provision of mental health services

- Support for provision of such services in relevant educational sites (eg, schools, tertiary institutions) and health care sites (eg, general practice, community health, pharmacies)

- Specific incentives for professionals who supervise the use of e-health-based treatment programs

- Integration of e-health interventions into usual-care systems

\section{How can we make things better for rural and remote} mental health?

First and foremost, rural and remote areas of Australia need to become attractive places to live and work. This requires major government regional development initiatives (Box).

In health care, evidence supports the use of appropriate models of service delivery. ${ }^{11}$ Rather than search for new models, we need to systematically apply what we already know. Despite a multitude of piecemeal government initiatives, there is no overall primary health care strategy, and, in particular, no strategy for rural primary care. In the absence of a strategy, coordination, maximising efficiency, and optimisation through organisational development is not possible.

What are some of the other solutions for rural and remote Australia? Changing the way psychiatrists practise to provide more opportunities for GPs to consult with them about their patients would help. Telepsychiatry is a partial solution, with obvious constraints. Self-help manuals and telephone-based interventions are well established and probably best used as adjuncts. More recently, self-help sites on the Internet, such as MoodGYM, a free self-help program to teach cognitive behaviour therapy skills, have been reported to produce positive outcomes. ${ }^{12}$ However, poor access to broadband and high telecommunication charges, as well as inexperience in using computerbased services, limit the applicability of telephone and Internet interventions in rural and remote areas. On the other hand, providing psychological treatments in groups makes good use of the scarce workforce ${ }^{13}$ and is now covered by the MBS.

\section{Multidisciplinary models for rural and remote Australia}

We need multidisciplinary models specifically for the circumstances of rural and remote Australia, which may include clinical networks, shared care, ${ }^{14}$ and collaborative care, ${ }^{15}$ linking metropolitan specialists with rural practitioners. In comparable health care systems (eg, United States and United Kingdom), these models have been achieved through systematic application of knowledge about organisational change as a specific part of the primary care strategy.

In rural areas, we need to build multidisciplinary teams around general practice that can cover the spectrum of mental disorders. These teams should include suitably trained psychologists, mental health and practice nurses, social workers and occupational therapists. Practice nurses have a potentially important role, including counselling and case management. In more remote areas with a high proportion of Indigenous patients, we need different models involving specially trained Aboriginal mental health workers supported by mental health nurses and specialists.

Fee-for-service needs to give way to payment-for-teamwork. To build these teams we need a clear workforce strategy. There are at least two concerns for psychologists, social workers and occupational therapists using the new item numbers. They lack experience in working with GPs, and, for the item numbers, there is no registration requirement to demonstrate training in specific interventions. 


\section{A rural and remote workforce strategy}

Recently, the Australian Psychological Society identified persistent issues affecting rural and remote practitioners: professional development, placement and training for rural psychologists in rural areas, and attracting psychology students and graduates to rural areas. ${ }^{16} \mathrm{On}$ the assumption that students are likely to stay where they train, rurally based training programs need to be developed, with specific financial incentives to increase the likelihood of students staying. Some universities in the UK and the US offer postgraduate programs to train psychologists and nurses to deliver therapies for common adult mental health disorders in primary care. The programs in the UK are usually for 1 year, comprising academic work and practical clinical placement work, and students are employed by the National Health Service. The university programs in the US tend to be postdoctoral fellowships that involve 2 years' paid full-time training and service experience, to prepare psychologists to work in clinical service, research and training settings associated with primary medical care. Similar programs could be established in Australia.

In addition to providing relevant community-based training, the rural and remote workforce will require continuing professional development and clinical supervision. University departments of rural health have considerable experience in developing and managing these workforce solutions for general practice and for allied health professionals. The Department of Health and Ageing will fund an academic in the field of mental health for each of the 11 university departments of rural health, which will go a long way towards implementing known workforce solutions. Offering a bursary program to attract psychology, social work, occupational therapy, and nursing students to undertake placements in rural and remote areas would give immediate benefits, including retaining the current workforce and recruiting graduates. The NSW Government offers up to $\$ 800$ per student in bursaries for psychology students undertaking rural and remote clinical placements. Federally funded bursaries for medical and pharmacy students should be extended to mental health professionals in rural training placements.

In the long run we need:

- new community-based, interprofessional training programs;

- incentive payments for health professionals to establish and maintain their practice in rural and remote areas;

- increased direct employment schemes for rural workforce; and

- further development in shared care between general practice and specialist psychiatry and psychology. ${ }^{14,17}$

Unless action is taken immediately, the substantial new investment in mental health may fail the people of rural and remote Australia.

\section{Update: 2007-08 budget}

The Government will provide $\$ 20.6$ million over four years to increase mental health services in drought-affected communities, building on the COAG Mental Health - mental health services in rural and remote areas measure announced in the 2006-07 Budget. The measure will provide for more allied and mental health ... professionals such as social workers, psychologists, occupational therapists, and Indigenous health workers in drought-affected communities.

In addition, $\$ 10.1$ million will be provided over the two years from 2007-08 to individual Divisions of General Practice to support mental health professionals and community leaders responding to the psychological impact of drought. ${ }^{18}$

\section{Competing interests}

None identified.

\section{Author details}

James A Dunbar, MD, FRCPEdin, FRACGP, Director ${ }^{1}$

Ian B Hickie, MD, FRANZCP, Executive Director ${ }^{2}$

John Wakerman, MBBS, FFAPHM, Director ${ }^{3}$

Prasuna Reddy, PhD, MAPS, Chair, Rural Mental Health ${ }^{1}$

1 Greater Green Triangle University Department of Rural Health, Flinders and Deakin Universities, Warrnambool, VIC.

2 Brain and Mind Research Institute, University of Sydney, Sydney, NSW.

3 Centre for Remote Health, Flinders University and Charles Darwin

University, Alice Springs, NT.

Correspondence: director@greaterhealth.org

\section{References}

1 Murray CJ, Lopez AD. Global mortality, disability, and the contribution of risk factors: Global Burden of Disease Study. Lancet 1997; 349: 1436-1442.

2 Andrews G, Issakidis C, Sanderson K, et al. Utilising survey data to inform public policy: a comparison of the cost-effectiveness of treatment of ten mental disorders. Br J Psychiatry 2004; 184: 526-533.

3 Burgess P, Pirkis J, Buckingham B, et al. Mental health needs and expenditure in Australia. Canberra: Mental Health and Special Programs Branch, Australian Government Department of Health and Ageing, 2002. http:// www.health.gov.au/internet/wcms/publishing.nsf/Content/mental-pubs-mneeds (accessed Apr 2007).

4 Mental Health Council of Australia. Not for service. Experiences of injustice and despair in mental health care in Australia. Canberra: MHCA, 2005. http:// www.mhca.org.au/notforservice/documents/NFS_Finaldoc.pdf (accessed Apr 2007).

5 Hall WD, Mant A, Mitchell PB, et al. Association between antidepressant prescribing and suicide in Australia, 1991-2000: trend analysis. BMJ 2003; 326: 1008-1012.

6 Australian Government Department of Health and Ageing. COAG mental health. Hon Tony Abbott, Minister for Health and Ageing, and Hon Christopher Pyne, Parliamentary Secretary to the Minister for Health and Ageing. Joint press release, 9 May 2006. http://www.health.gov.au/internet/budget/publishing.nsf/ Content/budget2006-hmedia2.htm (accessed May 2007).

7 Hickie I, Groom G, McGorry P, et al. Australian mental health reform: time for real outcomes. Med J Aust 2005; 182: 401-406.

8 Wakerman J, Humphreys J. Rural health: why it matters. Med J Aust 2002; 176 : 457-458.

9 Hickie I, Davenport T, Luscombe G, et al. Is a real reform of the Medicare Benefits Schedule for psychiatrists in Australia economically, socially or professionally desirable? Australas Psychiatry 2006; 14: 8-14.

10 Australian Institute of Health and Welfare. Psychology labour force 2003. Canberra: AlHW, 2003. (Catalogue No. HWL 34.)

11 Wakerman J, Humphreys J, Wells R, et al. A systematic review of primary health care delivery models in rural and remote Australia 1993-2006. Canberra: Australian Primary Health Care Research Institute, College of Medicine and Health Sciences, Australian National University, 2006.

12 Griffiths KM, Christensen H. Review of randomized controlled trials for Internet interventions for mental disorders and related conditions. Clin Psychol 2006; 10: 16-29.

13 Hawkins KM, Reddy P, Bunker S. Evaluation of a stress management course in adult education centres in rural Australia. Aust J Rural Health 2007; 15: 107-113.

14 Campbell A. The evaluation of a model of primary mental health care in rural Tasmania. Aust J Rural Health 2005; 13: 142-148.

15 Gilbody S, Bower P, Fletcher J, et al. Collaborative care for depression: a cumulative meta-analysis and review of longer-term outcomes. Arch Intern Med 2006; 166: 2314-2321.

16 The Australian Psychological Society. APS member groups. Rural and remote psychology. News. http://www.groups.psychology.org.au/rrig/news/ (accessed Jan 2007).

17 Hickie IB, Davenport TA, Luscombe GM. Mental health expenditure in Australia: time for affirmative action. Aust N Z J Public Health 2006; 30: 119-122

18 Australian Government. Budget 2007-08. Health and ageing. Mental health increased mental health services for drought-affected communities. http:// www.budget.gov.au/2007-08/bp2/html/expense-20.htm (accessed May 2007).

(Received 25 Jan 2007, accepted 19 Apr 2007) 